\title{
Determining the life cycle of bolts using a local approach and the Dang Van criterion
}

\author{
Y. FARES, M. CHAUSSUMIER, A. DAIDIE and J. GUILLOT \\ INSA, 135 avenue de Rangueil, 31077 Toulouse cedex 4, France, Laboratoire Génie Mécanique de Toulouse, équipe COSAM
}

\begin{abstract}
The fatigue behaviour of bolts under axial load has always been considered from the component point of view for which fatigue limit is usually taken equal to $50 \mathrm{MPa}$, and few results are available to designers for limited lifetimes.Here, we take up this problem from a material point of view using a local approach.For each case of fatigue testing, using finite-element (FE) model of the bolt, we determine the stabilized local stress at the root of the first thread in contact with the nut.To characterize bolt behaviour with these numerical results, we use Dang Van multiaxial fatigue criterion for which we extend application to the medium fatigue life.These results can be correlated with the experimental numbers of cycles to failure to determine material parameters of the generalized criterion.Using statistical Gauss method, we can make lifetime predictions for any level of risk of failure.In addition, we propose an analytical model to rapidly determine the local stress condition from nominal loading data (mean stress and alternating stress).This model dispenses us from a new modelling if the bolt is stressed in the same manner as the bolts used for behaviour characterization. Using this model and the generalized criterion, it is extremely easy to make lifetime predictions whatever the risk considered.
\end{abstract}

Keywords bolt; Dang Van criterion; fatigue life; multiaxial fatigue.

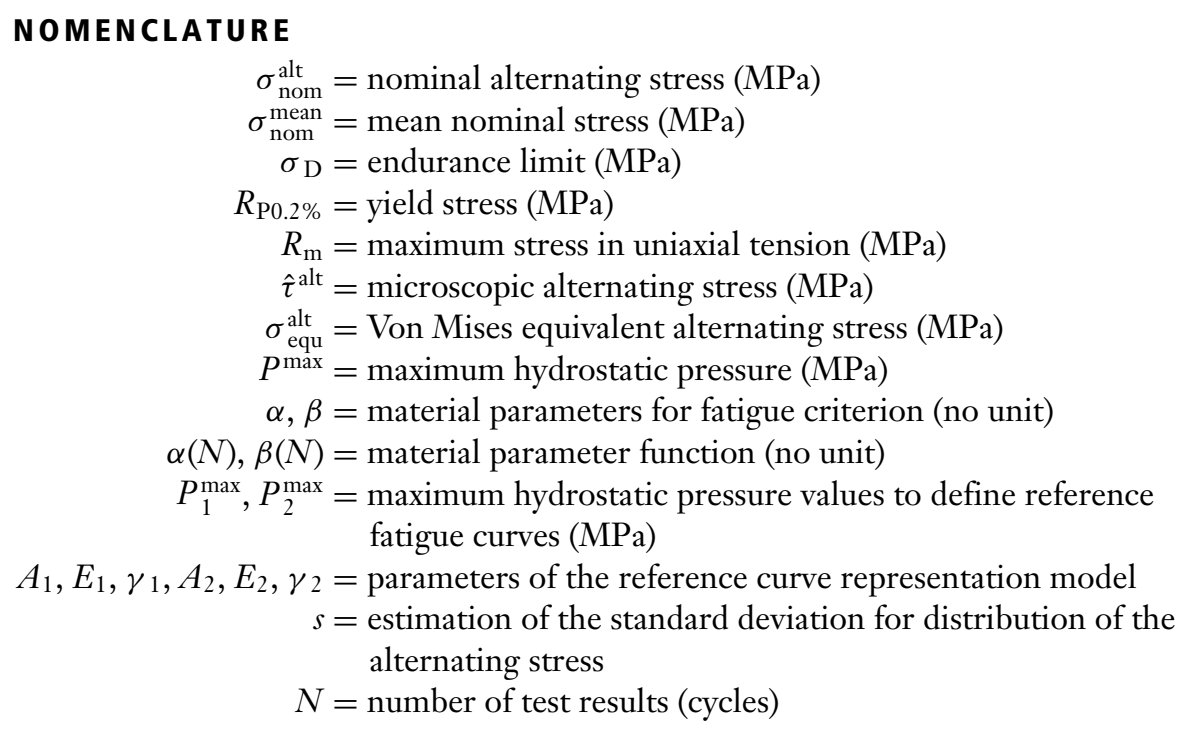

\section{INTRODUCTION}

Designing of the bolted assemblies inevitably involves knowledge of the fatigue strength of the bolt itself. At

Correspondence: Y. Fares. E-mail: faresmotors@hotmail.com present, this characteristic is obtained from standardized fatigue tests under an axial load defined by standard NFE 27-009. ${ }^{1}$ The endurance limit, noted $\sigma_{\mathrm{D}}$, is taken from European norm NFE 27-030 and from recommendations VDI 2230. ${ }^{3}$ By definition, it corresponds to the maximum nominal alternated stress $\sigma_{\text {nom }}^{\text {alt }}$, which does not lead to failure at $10^{7}$ cycles. Data are also available in [4] 
and [5]. All these experimental results allow the following conclusions:

- the endurance limit $\sigma_{\mathrm{D}}$ has little dependence on the mean nominal stress $\sigma_{\text {nom }}^{\text {mean }}$ when the latter corresponds to the usual values applied in bolted assemblies, that is between $50 \%$ and $80 \%$ of the yield stress $R_{P 0.2 \%}$;

- for a given diameter, the endurance limit $\sigma_{\mathrm{D}}$ is practically independent of the quality class of the bolt and is of the order of $50 \mathrm{MPa}^{4}$;

- the endurance limit $\sigma_{\mathrm{D}}$ diminishes significantly as the bolt's diameter increases.

To determine the endurance limit of an axial stressed bolt for a failure probability $\mathrm{P}_{\mathrm{r}}$, we can use the method proposed by CETIM organization ${ }^{6}$ based on Haigh's uniaxial fatigue model (Fig. 1):

However, even for the case of an axially stressed bolt, this type of fatigue diagram does not allow lifetime prediction if the nominal alternated stress $\sigma_{\text {nom }}^{\text {alt }}$ applied is greater than the endurance limit $\sigma_{\mathrm{D}}$ (case of medium fatigue life). Furthermore, it does not allow lifetime prediction for bolts submitted to several independent sources of stress (torsion-traction and flexion).

To remedy these inconveniencies, we suggest using a multiaxial fatigue criterion, as it is done commonly and successfully in some other fields of mechanical design (automotive design).

To do that, we consider the bolt as a mechanical part stressed in multiaxial fatigue in the same way as a drive shaft, a wheel spindle or a rail. For the latter, the designing method in fatigue involves two steps. The first step is the characterization of the fatigue material behaviour. This characterization is most often performed from fatigue tests under uniaxial loads. These tests determine the material parameters of the fatigue criterion. In our case, finite-element (FE) model of the bolt is necessary to determine the local stress. The second step results in the

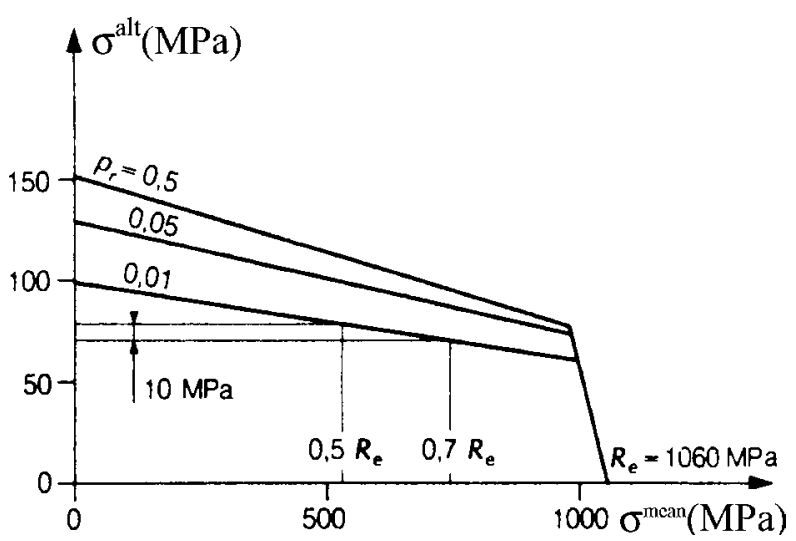

Fig. 1 Haigh diagram for a Class 12.9 diameter 12 bolt. evaluation of stress distribution in the most critical zone of the mechanical part. Then, this stress state is compared to the multiaxial fatigue characteristics using the multiaxial fatigue criterion.

In the present paper, we will describe the first step of this approach: characterization of the multiaxial fatigue behaviour of the material. For this characterization, we use the results of tests conducted on bolts and not tests conducted on conventional (smooth) fatigue test samples. That is simply because we need FE model of the bolt to determine the stress distribution at the thread root, which is the fatigue failure zone.

\section{CHARACTERIZATION UNDER STATIC CONDITIONS}

\section{Monotonic traction test}

Characterization of bolts behaviour in static conditions follows the same procedure as that for the materials themselves. The bolts have diameter M10 and the material used is $42 \mathrm{CrMo} 4$ in class 8.8 . These bolts were subjected to hardening and tempering heat treatment after cold rolling.

We decided to perform two types of monotonic static tests track up to rupture. The first test was done on a standardized smooth test sample from a bolt ${ }^{7,8}$ to determine the mechanical characteristics of the material that will be introduced into FE model. The second test was made on bolt itself in order to validate the FE model. After the first type of test, the yield stress $R_{P 0.2 \%}$ and the ultimate tensile stress $\mathrm{R}_{\mathrm{m}}$ were found to be $805 \mathrm{MPa}$ and $855 \mathrm{MPa}$. Moreover, elastic modulus $\mathrm{E}$ and Poisson's ratio $v$ are $216500 \mathrm{MPa}$ and 0.3 , respectively.

\section{Cyclic tensile properties}

Given the fact that it was impossible to perform lowcycle fatigue tests with total imposed deformation, we conducted bibliographical research on the matter. Various authors $^{9-11}$ found that, as a general rule, softening characterizes the materials with a tensile strength to elastic limit ratio $\mathrm{R}_{\mathrm{m}} / \mathrm{R}_{\mathrm{e}}$ less than 1.2; on the contrary, hardening characterizes the materials with $R_{m} / R_{e}$ greater than 1.4. In our case, this ratio is equal to 1.04 : We expect cyclical softening of the material and the cyclical strain-hardening curve to fit in below the monotonic curve as shown in (Fig. 2), where $\sigma$ is the true stress and $\varepsilon_{\mathrm{p}}$ is the equivalent plastic strain. ${ }^{12}$

To simulate the cyclic loading in Abaqus (Abaqus Inc., Providence, RI, USA), we chose linear kinematic cyclic monotonic hardening model. This model is suited for most metals subjected to cyclic loading conditions. This evolution law is the linear Ziegler 


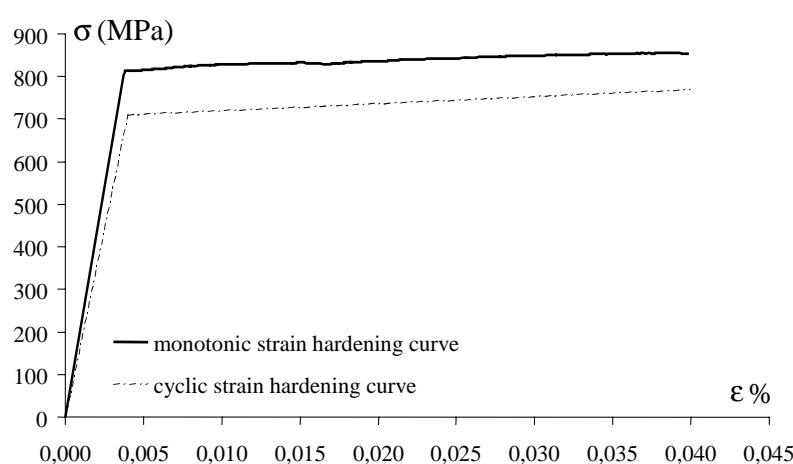

Fig. 2 Monotonic and cyclical strain-hardening curves for 304 steel.

hardening law

$\dot{\alpha}=C \frac{1}{\sigma^{O}}(\sigma-\alpha) \dot{\bar{\varepsilon}}^{p l}$,

where $\dot{\bar{\varepsilon}}^{p l}$ is the equivalent plastic strain rate and $C$ is the kinematic hardening modulus. To continue our study, we considered the linear hardening strain monotonic curve as the linear hardening strain cyclic one. We provide only two data pairs to define this linear behaviour: the yield stress $805 \mathrm{MPa}$ at zero plastic strain and a yield stress, $\sigma=855 \mathrm{MPa}$ at a finite plastic strain value $\varepsilon^{\mathrm{pl}}=0.45$.

\section{Fatigue test on bolts}

We performed traction fatigue tests on bolts with M10 diameter in class 8.8 in the presence of the nut (Fig. 3). These tests were carried out under different levels of mean nominal stress, close to those actually implemented in real assemblies: $50 \%, 70 \%$ and $80 \%$ of the yield stress of the material.

Only test results under mean stresses of $50 \% R_{P 0.2 \%}$ and $80 \% R_{P 0.2 \%}$ were used to characterize fatigue behaviour.

The results enabled us to construct fatigue curves. For these levels of mean nominal stress, several levels of alternated stress were applied, varying between $70 \mathrm{MPa}$ and $120 \mathrm{MPa}$ as shown in the graph of (Fig. 4). The results obtained under mean stress of $70 \% R_{P 0.2 \%}$ were retained to validate the approach.

\section{FE model of the bolt}

An axisymmetric model for the bolt-nut assembly was developed using the I-deas CAD software (UGS, Plano, TX, USA). Several levels of meshing fineness, especially on the bolt thread root and contact between the bolt and the nut were implemented and analyzed by simulation using the Abaqus program to search for the best trade-off between the quality of the results and calculation time. The size of all elements is $0.01 \mathrm{~mm}$ except for the contact surfaces.

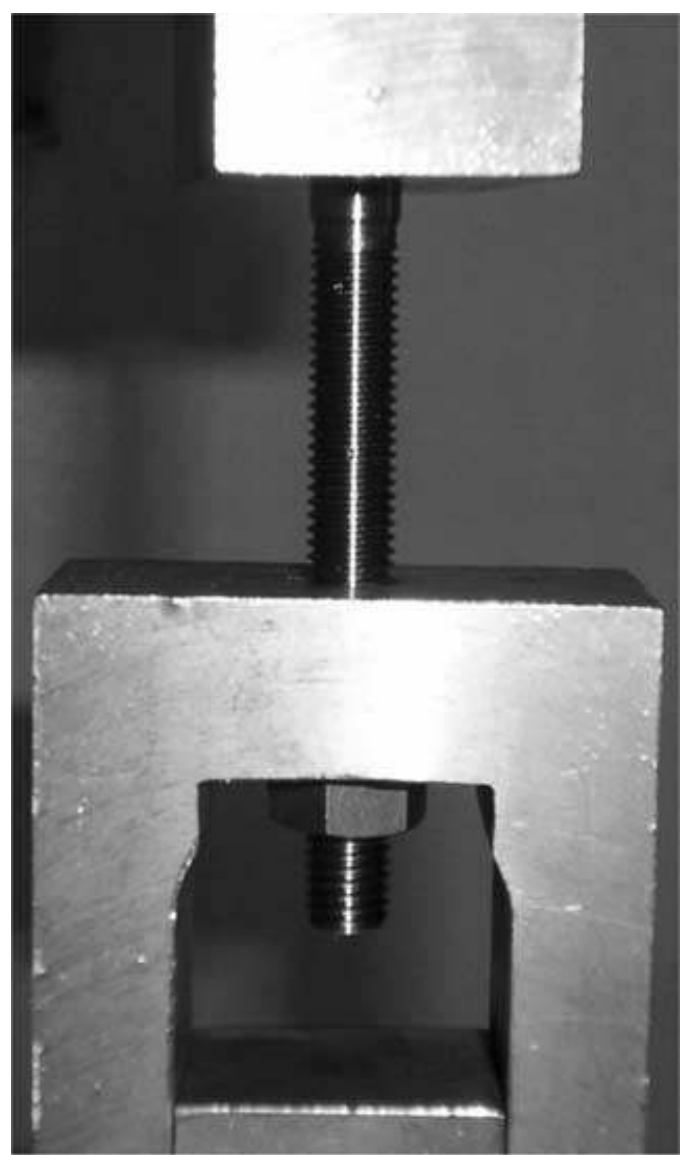

Fig. 3 Assembly of fatigue test on bolt M10.

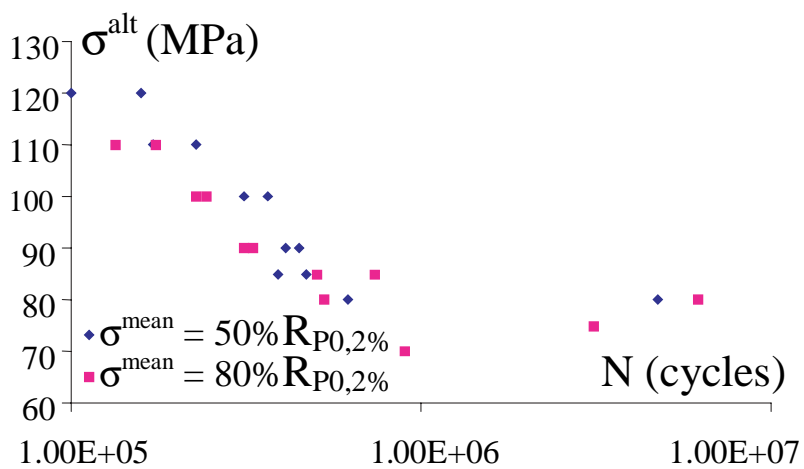

Fig. 4 Results of traction fatigue tests on $42 \mathrm{CrMo} 4$ steel class 8.8 bolts.

Concerning this zone, we choose $0.015 \mathrm{~mm}$ from one side (bolt) and $0.04 \mathrm{~mm}$ (nut) from the other side; because the master surface (nut) should coincide with the surface with the coarser mesh. We chose four node elements after a comparative study made between four-node elements and eight-node elements. Due to the very small size of the elements, we had the same response on local stresses and deformations but the time calculation is greater for eightnode elements. 
Abaqus defines the contact conditions between two bodies using a strict 'master-slave' algorithm. We have chosen a small sliding approach to account for the relative motion of the two surfaces forming the contact pair. Since this approach assumes that the two bodies undergo large motions there will be relatively little sliding of one surface along the other. The friction coefficient is fixed to $0.15 .{ }^{30}$

The notch root radius of the bolt and the nut are respectively $0.216 \mathrm{~mm}$ and $0.108 \mathrm{~mm}$. The value of the theoretical stress concentration factor $\mathrm{K}_{\mathrm{t}}$ is 4.5 . This value is referred to the first thread under load, the more critical one (Fig. 5).

The figure below (Fig. 6) shows details of the meshing on the bolt and nut threads in contact.

To validate this model, we simulated a monotonic traction test and compared the curve for traction thus obtained

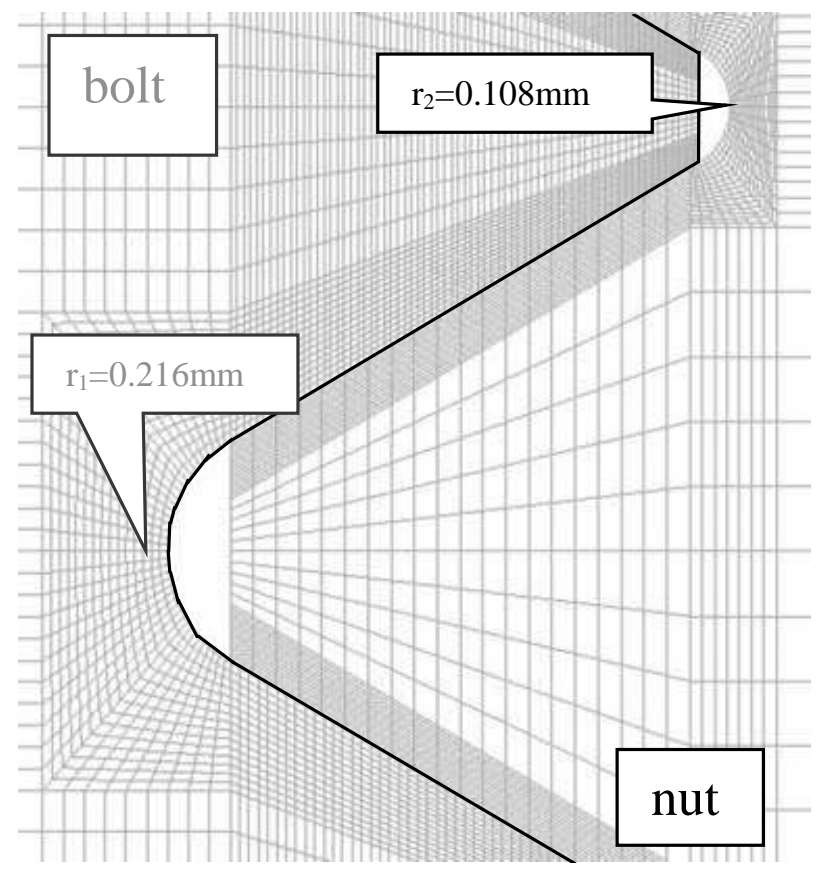

Fig. 5 Change in theoretical stress concentration factor Kt and the real stress concentration factor $\mathrm{K} \sigma$ with nominal stress.

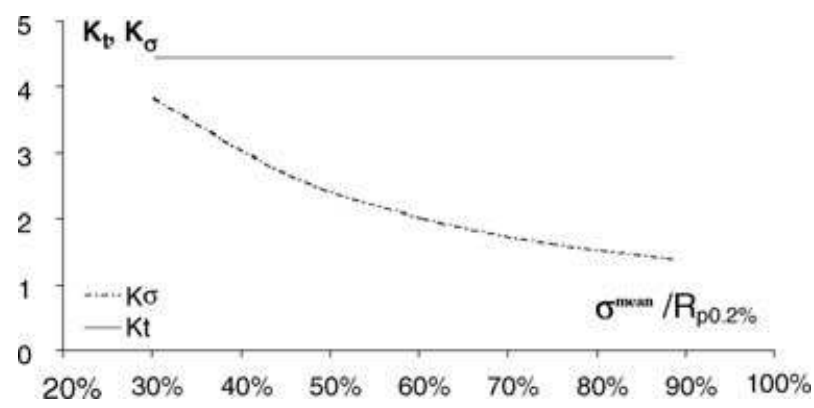

Fig. 6 Detail view of FE model for the bolt.

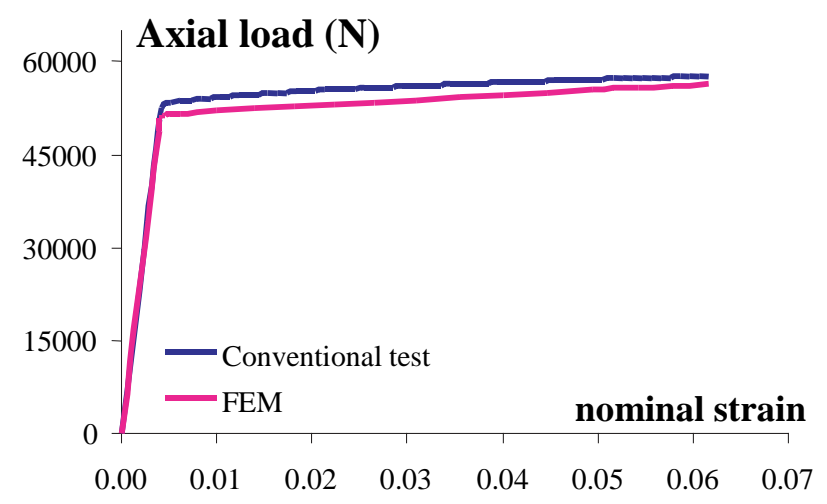

Fig. 7 Comparison of experimental and numerical tensile curves.
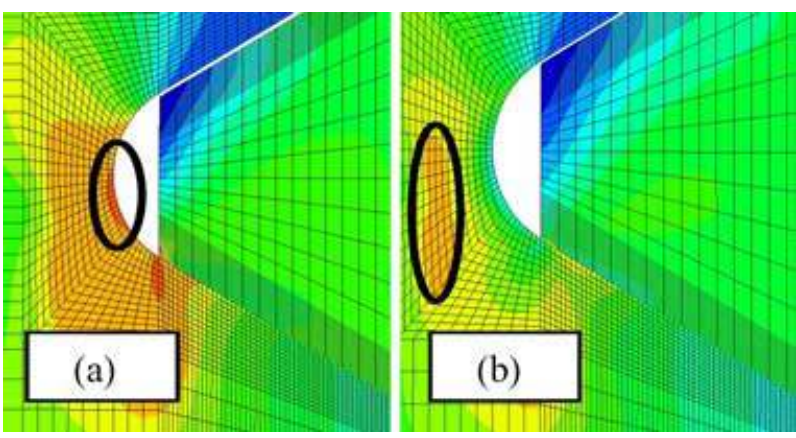

Fig. 8 (a) and (b): Change in Von Mises stresses in the first thread in contact for a mean stress equal to $80 \% R_{\mathrm{p} 0.2 \%}$ and $90 \mathrm{MPa}$ of alternating stress during the stabilized cycle.

with an experimental curve. Figure 7 shows the result of this comparison.

We can note a good correlation between the two curves with deviation to within $2 \%$. We can consider our FE model to be capable of providing reliable estimations of the stress conditions at the thread root during simulations of fatigue tests.

For each case of fatigue traction load, we simulated several stress cycles so as to obtain a stabilized stress condition at the thread root. Figure 8 shows the change in stress and its distribution over the first thread in contact during the stabilized cycle. The first view (Fig. 8a) corresponds to maximum nominal stress. The second view (Fig. 8b) represents minimum nominal stress. In the first case, we can notice two critical zones, at the thread root of the bolt and at the beginning of the contact with the nut. We determined the microscopic equivalent stress and the maximum hydrostatic pressure for the most loaded elements. These results plotted simultaneously on $\hat{\tau}^{\text {alt }}-P_{\max }$ graph show that the alternated stress of the thread root element is greater than the one corresponding to the element located at the beginning of contact: This justifies the fracture zone taken in consideration. 
The maximum Von Mises stress is $934 \mathrm{MPa}$. In the second case, the most heavily loaded zone is carried under the surface; the maximum Von Mises stress has a value of $720 \mathrm{MPa}$. This movement of the critical zone is quite naturally due to local yielding at the root that appeared during the first cycles.

Otherwise, the plastic zone depth is $0.21 \mathrm{~mm}$ and size ahead of the notch tip is $0.15 \mathrm{~mm}^{2}$.

\section{Multiaxial fatigue criterion}

Although the loading applied to the bolt is uniaxial, the stress condition at the root of the first thread in contact is multiaxial. Obviously, this is due to the geometry. In these conditions, designing in fatigue of the bolt requires the use of a multiaxial fatigue criterion.

Fatigue behaviour of materials has been exhaustively studied since Wöhler's first works. The multiaxial nature of loads imposed on mechanical parts naturally led researchers to take an interest in the ways in which the nature of the load influences fatigue behaviour. Many approaches have been developed to propose designing criteria in multiaxial fatigue. These approaches can be classified into two main families: methods based on defining an equivalent magnitude (energy, stress or deformation) ${ }^{14-19}$ and methods based on searching for a critical plane. ${ }^{20-25}$

In the recent bibliography, we found numerous prediction methods, as with Lazzarin, ${ }^{26} \mathrm{Akrache}^{27}$ and Constantinescu. ${ }^{28}$ All these methods have been subject to discussion, but have never been verified on complex parts like bolts.

Among all the available criteria, we chose Dang Van's criterion usually used in France in automotive and rail design because it allows us to take into account multiaxial stress states induced by eccentric loadings on bolted joints. ${ }^{23}$ In this criterion, Dang Van postulates that crack initiation may occur in the most unfavourable oriented grains, which was subjected to a plastic deformation even if the bulk stress is elastic. This criterion is constructed on a microscopic approach to fatigue behaviour and the research for a critical shearing plane. It suggests that cracking factors are firstly microscopic stress $\hat{\tau}_{\underline{\underline{n}}}$ on a critical plane with normal $\vec{n}$ and secondly microscopic hydrostatic pressure $P$. The argument of Dang Van was that if shakedown were achieved at the grain level, a crack would never initiate. It is based on a local approach where the plastic strain is accumulated due to external loading and estimated at a scale of the order of a few grains. The Dang Van criterion is expressed as

$\max _{\underline{n}}\left\{\max _{t}\left[\left\|\hat{\underline{\tau}}_{\underline{\mathrm{n}}}(t)\right\|+\alpha \cdot p(t)\right]\right\} \leq \beta$.

Using a micro-macro transition method, we can define the microscopic stresses at the grain level from macroscopic stresses state $\underline{\underline{\sigma}}_{\mathrm{loc}}$ calculated with FE model.
It is well known that the microscopic stress tensor $\sigma$ and the macroscopic stress tensor $\Sigma$ are related by the following formula

$\sigma=A \cdot \Sigma+\rho$,

where $\rho$ is the microscopic residual stress and $A$ is the fourth order tensor of elastic stress localization..$^{28}$

Although it is a delicate matter to implement this criterion when the load is complex, it nevertheless provides good predictions except for loads leading to stress conditions with out-of-phase combined loading. ${ }^{27,32,33}$

Application of this criterion to our case simplifies its use: given that the tests were conducted under uniaxial external load, all the components of the local strain tensor $\underline{\sigma}_{\text {loc }}$ are in phase and the principal directions of strains are constant. In this case, the criterion can be reduced to the following expression

$\hat{\tau}^{\mathrm{alt}} \leq \alpha \cdot P^{\max }+\beta$.

where $\hat{\tau}^{\text {alt }}$ and $P^{\max }$ respectively represent alternate microscopic stress and maximum microscopic hydrostatic pressure. $\alpha$ and $\beta$ are material parameters that can be readily identified from endurance limits.

As most of these criterion type, the author suggested this one to show the influence of the multiaxial stress on the fatigue resistance for high number of cycles. This criterion can be extended to the field of medium life (limited endurance), on condition that plasticity remains confined and that the macroscopic adaptation phase is rapid enough for the corresponding damage to be negligible with respect to overall damage. This is indeed the case where the plasticized zone remains confined in the thread root.

Generalizing the Dang Van criterion to the endurance limited domain leads to formulating it as follows:

$\hat{\tau}^{\mathrm{alt}}(N)=\alpha(N) \cdot P^{\max }+\beta(N)$,

in which expressions $\alpha(N)$ and $\beta(N)$ are characteristic parameter functions of the material that depend on the number of cycles to rupture $N$.

To identify these parameter functions, the first method that comes to mind is to determine two fatigue curves independently of each other. For a given number of cycles to failure, the $\hat{\tau}^{\text {alt }}=P_{\max }$ boundary line of the criterion, with slope $\alpha(N)$ and ordinate at the origin $\beta(N)$, will rest on these two $\mathrm{S}-\mathrm{N}$ reference curves. However, while this method is easy to apply, it does not allow establishing correct probabilistic predictions as to lifetime as each of the curves is defined with its own statistic.

To remedy this shortcoming, we propose a global identification of both material parameter functions by statistical processing of all the test results. To do it, we use a formulation of the criterion in which we introduce two reference S-N curves defined for the two maximum 
hydrostatic pressures $P_{1}{ }^{\max }$ and $P_{2}{ }^{\max }{ }^{29}$ These two reference $\mathrm{S}-\mathrm{N}$ curves are represented with the following relations deduced from relation (5)

$\hat{\tau}_{1}^{\mathrm{alt}}(N)=\alpha(N) \cdot P_{1}^{\max }+\beta(N)$,

$\hat{\tau}_{2}^{\text {alt }}(N)=\alpha(N) \cdot P_{2}^{\max }+\beta(N)$.

From these two relations, it is easy to express the functions $\alpha(N)$ and $\beta(N)$

$\alpha(N)=\frac{\hat{\tau}_{1}^{\mathrm{alt}}(N)-\hat{\tau}_{2}^{\mathrm{alt}}(N)}{P_{1}^{\max }-P_{2}^{\max }}$,

$\beta(N)=\frac{P_{1}^{\max } \cdot \hat{\tau}_{2}^{\text {alt }}(N)-P_{2}^{\max } \cdot \hat{\tau}_{1}^{\text {alt }}(N)}{P_{1}^{\max }-P_{2}^{\max }}$.

The two reference curves can be represented using the Stromeyer model ${ }^{31}$

$\hat{\tau}^{\text {alt }}=E+\frac{A}{N^{\gamma}}$.

This representation model offers the advantage of being simple and capable of adapting to the fatigue curve shapes obtained with fatigue tests on bolts. In particular, they allow the asymptotic trend of the fatigue curve to be represented. Furthermore, its formulation in stress allows it to be used by the smoothing method recommended by standard NF A03-405 ${ }^{13}$ (least-squares method). We consider stress to be a random variable with constant standard deviation, regardless of the number of cycles.

We now have a global model to characterize the fatigue behaviour of bolts. This model brings six parameters into play (three per reference curve) among which two correspond to endurance limits. The two reference $\mathrm{S}-\mathrm{N}$ curves used in the generalized formulation of the fatigue criterion are respectively defined for hydrostatic pressure $P_{1}^{\max }$ $(538 \mathrm{MPa})$ and $P_{2}^{\max }(566 \mathrm{MPa})$. These values have been evaluated with the FE model in the bolt thread root from the upper and lower bound values of the tests $\left(\sigma_{\text {nom }}^{\text {mean }}=\right.$ $50 \% R_{P 0.2 \%} ; \sigma_{\text {nom }}^{\text {alt }}=70 \mathrm{MPa}$ and $\sigma_{\text {nom }}^{\text {mean }}=80 \% R_{P 0.2 \%}$; $\sigma_{\text {nom }}^{\text {alt }}=120 \mathrm{MPa}$ ).

(Fig. 11). Table 1 summarizes the values for the six other parameters of the global model of the generalized criterion.

In this table, $s$ represents the estimation of the standard deviation for distribution of microscopic alternating

Table 1 Generalized fatigue model parameter values

\begin{tabular}{lllll}
\hline$P_{1}^{\max }, P_{2}^{\max }(\mathrm{MPa})$ & $A$ & $\gamma$ & $E$ & $s(\mathrm{MPa})$ \\
\hline 538 & 400118 & 0.7 & 71 & 14 \\
566 & 1027770 & 0.8 & 70 & \\
\hline
\end{tabular}

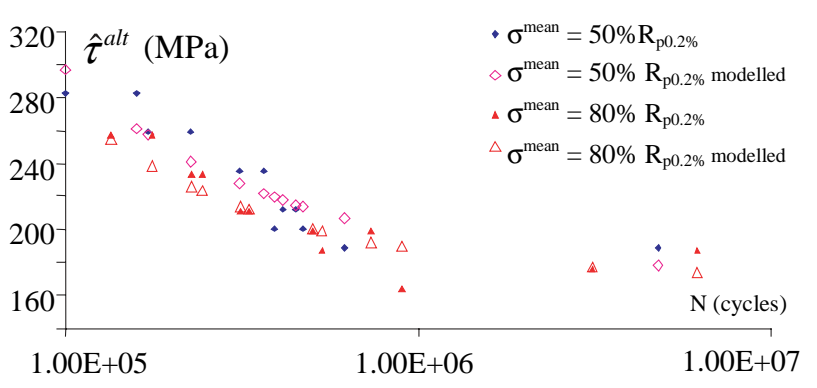

Fig. 9 Results of global smoothing using the Stromeyer model.

stress. It is given by the following relation

$s=\sqrt{\frac{\sum_{i=1 \ldots n}\left(e_{i}^{\mathrm{res}}\right)^{2}}{n-p}}$,

where $e_{\mathrm{i}}^{\text {res }}$ represents the deviation between the experimental microscopic alternating stress and the microscopic alternated stress calculated using the model, $n$ the number of experimental points (here 26) and $p$ the number of parameters of the model used (here six). This standard deviation translates the dispersion of test results, where dispersion is related to the material and accentuated by the notch effect.

The figure below (Fig. 9) shows the results obtained in equivalent alternated stress. Note that the results obtained using the generalized model do not align on a fatigue curve. This is normal as they correspond to the various hydrostatic pressure values rather than to the reference curves defined in the model.

It is now possible to plot the boundary lines for the criterion retained for the various values of the number of cycles to failure. The fact that we have processed all the test results using a global model means we can plot these straight lines not just as mean values (corresponding to a probability of survival $50 \%$ ), but also for a lower level of risk. Figure 10 illustrates the results for $2 \times 10^{5}, 10^{6}$ and $10^{7}$ cycles; we can observe a continuous decrease of the slope (the values are respectively $-0.70,-0.34,-0.09$ ). On these curves, the continuous straight line represents the boundary line for a probability of survival of $50 \%$ and the dotted straight line the boundary line for $0.1 \%$ risk of failure deduced from the first one using the estimation of the standard deviation. ${ }^{13}$

\section{LIFETIME PREDICTION FOR A BOLTED ASSEMBLY}

The global model thus defined allows predictions to be made on lifetime considering a given risk. To make this prediction, we need to know the stress condition at the thread root for the load studied in (Figs 11 and 12). 
The graphs below show the variability of the two quantities governing the criterion: $\hat{\tau}^{\text {alt }}$ and $P^{\max }$ as a function of the nominal load characteristics. As we can see in these figures, these quantities change in almost linear fashion with the nominal value of alternated stress.

Using these results we can establish laws for correlation between the four quantities we are interested in here, that is, on the one hand, loading data $\sigma_{\text {nom }}^{\text {mean }}, \sigma_{\text {nom }}^{\text {alt }}$ and on the other, $\hat{\tau}^{\text {alt }}, P_{\max }$. Processing of the results from numerical
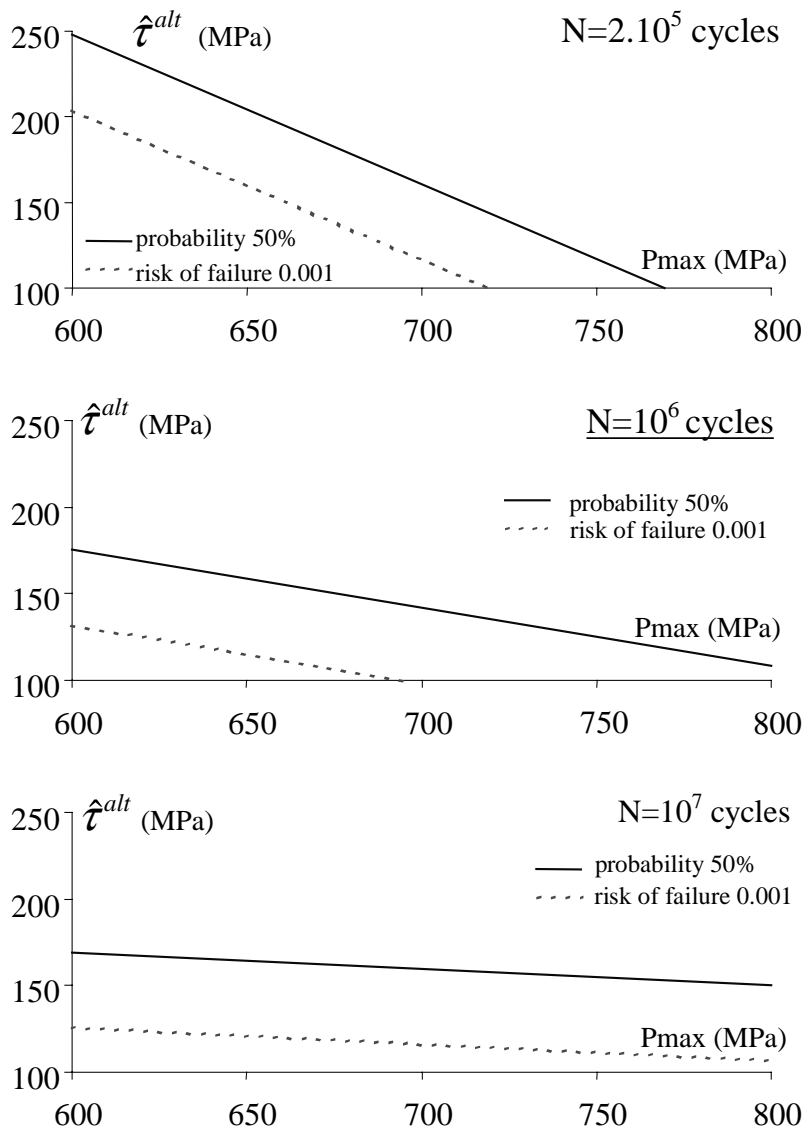

Fig. 10 Boundary lines for the criterion as a mean value and a risk of failure 0.001 for $2 \times 10^{5}, 10^{6}$ and $10^{7}$ cycles. simulations gave the laws for change (Figs 11 and 12)

$$
\begin{aligned}
\hat{\tau}^{\mathrm{alt}}= & \left(-0.16 \cdot \frac{\sigma^{\text {mean }}}{R_{p 0.2 \%}} R_{p 0.2 \%}+2.45\right) \cdot \sigma_{\mathrm{alt}} \\
+ & \left(10.28 \times \frac{\sigma^{\text {mean }}}{R_{p 0.2 \%}} \times 100-6.59\right), \\
P^{\mathrm{max}}= & \left(-0.18 \cdot \frac{\sigma^{\text {mean }}}{R_{p 0.2 \%}} R_{p 0.2 \%}+0.21\right) \cdot \sigma_{\mathrm{alt}} \\
& +\left(102.72 \times \frac{\sigma^{\text {mean }}}{R_{p 0.2 \%}} \times 100+480.48\right) .
\end{aligned}
$$

With these two relations (12) and (13), the bolt's lifetime can be predicted for a given level of risk of failure. For example, for a bolt pre-stressed to $70 \% \mathrm{R}_{\mathrm{p} 0.2 \%}$ and subjected to a nominal alternating stress of $90 \mathrm{MPa}$, we obtain the values given in (Table 2 ).

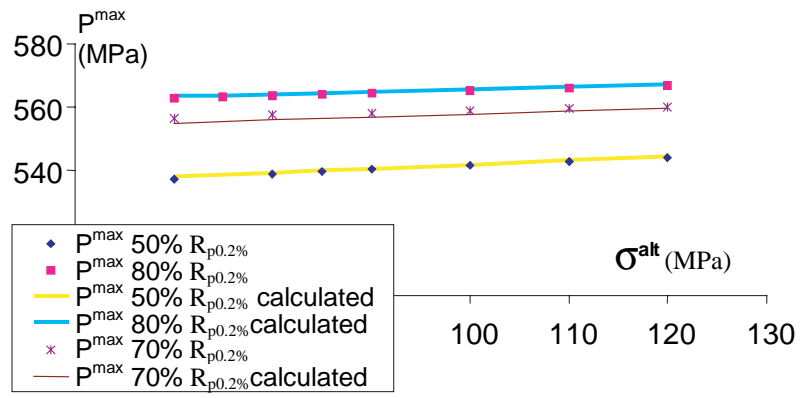

Fig. 11 Change in maximum hydrostatic pressure at the thread root with nominal alternated stress for three cases of pre-stress.

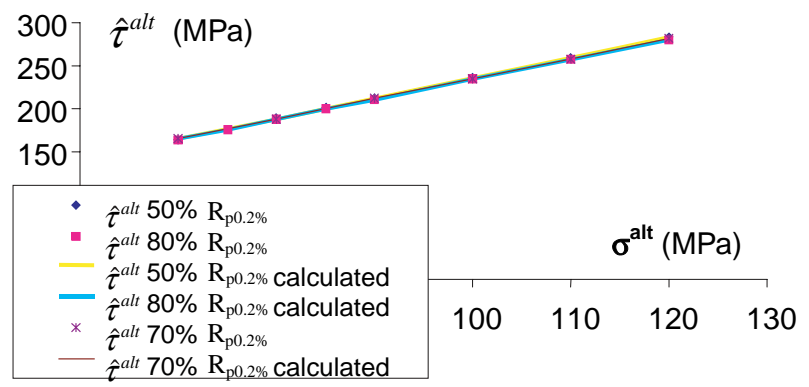

\begin{tabular}{|c|c|c|c|c|c|c|}
\hline \multirow[b]{2}{*}{$\sigma_{\text {nom }}^{\text {mean }}$} & & \multirow[b]{2}{*}{$\sigma_{\text {nom }}^{\text {alt }}$} & \multicolumn{2}{|l|}{ Tests } & \multicolumn{2}{|l|}{ Risk 50\% } \\
\hline & & & $\overline{N_{1}}$ & $\mathrm{~N}_{2}$ & $\mathrm{~N}_{3}$ & $\mathrm{~N}$ \\
\hline $70 \% R_{\mathrm{p} 0.2 \%}$ & $563 \mathrm{MPa}$ & $90 \mathrm{MPa}$ & $4 \times 10^{5}$ & $4.4 \times 10^{5}$ & $4.7 \times 10^{5}$ & $3.9 \times 10^{5}$ \\
\hline $70 \% R_{\mathrm{p} 0.2 \%}$ & $563 \mathrm{MPa}$ & $80 \mathrm{MPa}$ & $1.5 \times 10^{6}$ & $2.2 \times 10^{6}$ & & $1.2 \times 10^{6}$ \\
\hline $50 \% R_{\mathrm{p} 0.2 \%}$ & $402 \mathrm{MPa}$ & & & & & \\
\hline $80 \% R_{\mathrm{p} 0.2 \%}$ & $604 \mathrm{MPa}$ & & & & & \\
\hline
\end{tabular}

Fig. 12 Changes in alternated microscopic stress at the thread root with nominal alternated stress for three cases of pre-stress.

Table 2 Comparison of values for number of cycles to rupture for two cases of loading 


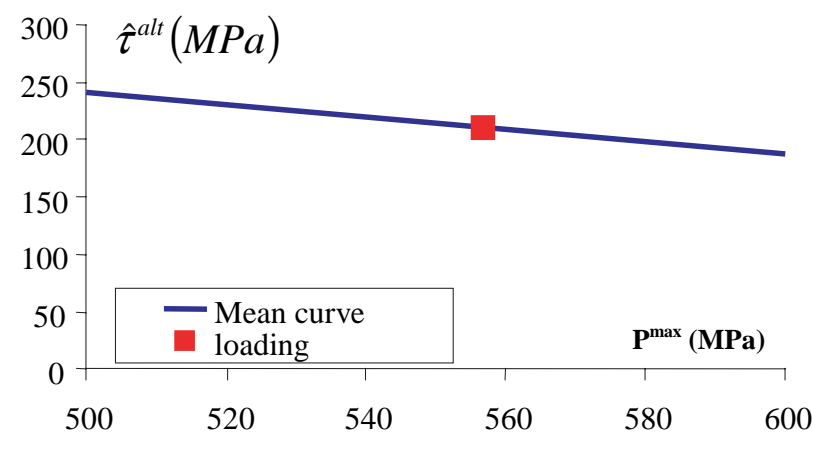

Fig. 13 Calculation of lifetime for a bolt pre-stressed to $70 \% R_{\mathrm{p} 0.2 \%}$ and stressed axially in fatigue at $90 \mathrm{MPa}$ for a risk of $50 \%$.

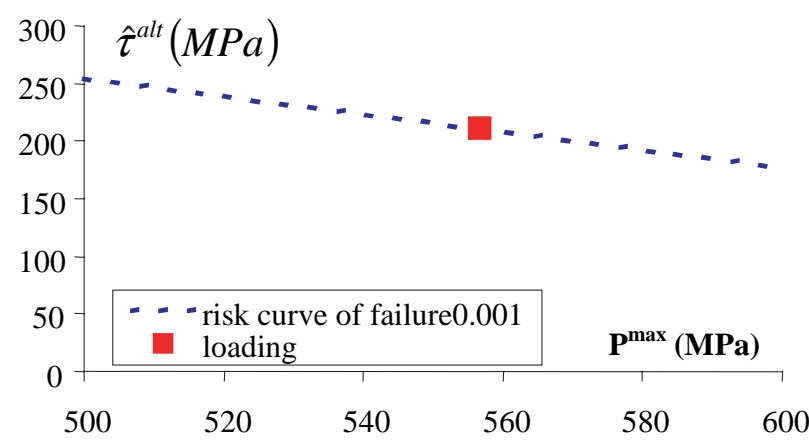

Fig. 14 Calculation of lifetime for a bolt pre-stressed to $70 \% R_{\mathrm{p} 0.2 \%}$ and stressed axially in fatigue at $90 \mathrm{MPa}$ for $0.1 \%$ risk of failure.

For a level of risk of $10^{-3}$ this lifetime would be $1.5 \times$ $10^{5}$ cycles (Figs 13 and 14) illustrate this calculation.

In the same context, the model can be easily used to establish the nominal level of alternated stress that we can apply in function of the pre-stress, the chosen life and security factor. For example, in the case of a bolt prestressed to $75 \% \mathrm{R}_{\mathrm{p} 0.2 \%}$ (i.e., $667 \mathrm{MPa}$ ), for which we want a lifetime of $3 \times 10^{6}$ cycles, with a risk of $0.1 \%$, the nominal alternated stress must not exceed 20.6 MPa. For a risk of $50 \%$, this stress can reach $81 \mathrm{MPa}$.

\section{CONCLUSION}

In this article, we have shown that it was possible to address the question of characterization and designing of bolts subjected axially to stress cycles using a material approach. The bolt is considered to be a mechanical part subjected to multiaxial fatigue. Having posited this, designing requires the use of a multiaxial fatigue criterion. Here, we opted for Dang Van's criterion in its simplified formulation for which we extended the range to the limited endurance domain. Formulation from the definition of the two fatigue reference curves allows to treat the set of test results for available bolts and to provide a global statistics usable for life prediction by considering level risks other then $50 \%$. Note, however, that for this type of approach, we need to dispose off a sufficient number of test results. FE model was developed to determine the local stress condition at the first thread root in contact, the location for fatigue failure initiating. This material approach of fatigue strength allows its use on different diameters of bolts. To do that, we just need an FE model to determine the local stresses at the notch thread.

The advantage of this local approach with the use of a generalized fatigue criterion is obvious: it means we can establish probabilistic predictions for any loading conditions, provided the criterion relates to local stress condition (thread root), within the characterization domain. In parallel, we analyzed our results with Crossland criterion. It leads to similar results considering the type of load. In a certain way, we use this comparison to verify our results and the approach proposed in the present article.

In the present work, we have not taken into account torsion torque related to the pre-tightening load. Tests are under way to study the influence of this torsion torque on resistance to fatigue of bolts.

\section{REFERENCES}

1 NFE 27-009 (1979). Eléments de fixation, essais de fatigue sous charge axiale.

2 NFE 25-030 (1984). Eléments de fixation, assemblages vissés.

3 VDI 2230 (2003). Systematische Berechnung Hochbeanspruchter Schraubenverbindungen. VDI Richtlinien.

4 Sayettat, C., Faurie, J. P. and Peyret, M. (1980). Bolted assemblies. Conception et Montage, CETIM.

5 Lieurade, H. P. (1977). Compléments en fatigue des boulons et des ensembles boulonnés en construction métalliques. Assemblage.

6 Brand, A. (1980). Calcul des pièces à la fatigue, Méthode du gradient. ISBN 2-85400-022-6, CETIM.

7 NF EN ISI 898-1 (1999). Caractéristiques mécaniques des éléments de fixation en acier au carbone et en acier allié - partie 1 : vis et goujons.

8 NF EN ISO 10002-1 (2001). Essai de traction, méthode d'essai à température ambiante.

9 Manson, S. S. and Hirschberg, M. (1964). Fatigue, An Interdisciplinary Approach. Syracuse University Press, Syracuse, NY, pp. 133-173.

10 Smith, R., Hirschberg, M. and Manson, S. S. (1963). Fatigue behaviour of materials under strain cycling in low and intermediate life range. Report NASA-TN.D. 1574 National Aeronautics and Space Administration.

11 Amzallag, C., Rabbe, P. and Pellissier Tanon, A. (1976). Fatigue oligocyclique des matériaux utilisés dans les centrales nucléaires à eau légère. Matériaux et Techniques 27, 323-324.

12 Bathias, C. and Bailon, J. P. (1997). La fatigue des matériaux et des structures. $2^{\mathrm{e}}$ édition revue et augmentée. Hermès, Paris. ISBN 2-86601-617-3.

13 NORME NF A03 405 (1992). Recueil des normes françaises, produits sidérurgiques. Essais mécaniques partie 2, Fatigue, mécanique de la rupture, 2. 
14 Gough, H. J. and Pollard, H. V. (1951). Some experiments on the resistance of metals under combined stresses. Aeronautical Research Council, Reports and Memoranda, $\mathrm{N}^{\circ} 2522$, London.

15 McDiarmid, D. L. (1973). A general criterion of fatigue failure under mutiaxial stress. 2nd International Conference on pressure vessel technology, San Antonio, pp. 851-862.

16 Crossland, B. (1956). Effect of large hydrostatic pressures on the torsional fatigue strength of an alloy steel. Fatigue of metals - International Conference - Sep London, pp. 138-149.

17 Sines, G. and Ohgi, G. (1981). Fatigue criteria under combined stresses or strains. Trans. ASME 103, 82-90.

18 Ellyin, F. and Kujawski, D. (1984). Plastic strain energy in fatigue failure. F. Eng. Mater. Technol. 106, 342-347.

19 Patterson, E. A. (1990). A comparative study of methods for estimating bolt fatigue limits. F. Fatigue Fract. Eng. Mater. Struct. 13, 59-81.

20 Findley, W. M. (1959). Theory of the effect of mean stress on fatigue of metals under combined torsion and axial load or bending. 7. Eng. Ind. 81, 301-306.

21 McDiarmid, D. L. (1991). A general criterion of high cycle multiaxial fatigue. 7. Fatigue Fract. Eng. Mater. Struct. 14, 429-453.

22 Socie, D. F. (1993). Critical plane approaches for multiaxial fatigue damage assessment. Adv. multiaxial fatigue, pp. 7-36.

23 Glinka, G., Plumtree, A. and Shen, G. (1995). A multiaxial fatigue strain energy density parameter related to the critical plane. 7. Fatigue Fract. Eng. Mater. Struct. 18, 37-46.

24 Dang Van, K. (1993). Macro-micro approach in high-cycle fatigue. Adv. multiaxial fatigue, pp. 120-130.
25 Morel, F. (2000). A critical plane approach for life prediction of high cycle fatigue under multiaxial variable amplitude loading. Int. F. Fatigue 22, 101-119.

26 Lazzarin, P. and Susmel, L. (2003). A stress based method to predict lifetime under multiaxial fatigue loading. F. Fatigue Fract. Eng. Mater. Struct. 26, 1171-1187, num 12.

27 Akrache, R. and Lu, J. (1999). Three dimensional calculations of high cycle fatigue life under out of phase multiaxial loading. 7. Fatigue Fract. Eng. Mater. Struct. 22, 527-534.

28 Constantinescu, A., Dang Van, K. and Maitournam, M. H. (2003). A unified approach for high and low cycle fatigue based on shakedown concepts. F. Fatigue Fract. Eng. Mater. Struct. 26, 561-568.

29 Desvignes, M. (1996). Critère de rupture multiaxial. Mech. Des. 2, 813-822.

30 Jien-Jong, C. and Yan-Shin, S. (1999). A study of the helical effect on the thread connection by three dimensional finite element analysis. Nucl. Eng. Des. 191, 109-116.

31 Bastenaire, F. (1976). Estimation et prevision statistiques de la résistance et de la durée des matériaux en fatigue. IRSID, Nov. 1976

32 Lu, J., Flavenot, J. F., Diboine, A., Lasserre, S., Froustey, C., Bennebach, M. and Palin-Luc, T. (1996). Development of a general multiaxial fatigue criterion for high cycles of fatigue behavior prediction. In: Multiaxial fatigue and design (Edited by Pineau, A., Cailletaud, G. and Lindley, T. C.). The European Structural Integrity Society, ESI21. Mechanical Engineering Publications, London, pp. 477-487.

33 Galtier, A. (1993). Contribution à l'étude de l'endommagement des aciers sous sollicitations uni ou multiaxiales. Thèse de Doctorat de l'ENSAM. 